\title{
AB INITIO STUDY OF THE ROTATIONAL-TORSIONAL SPECTRUM OF METHYL FORMATE
}

\author{
M. L. Senent, ${ }^{1}$ M. Villa, ${ }^{2}$ F. J. Meléndez, ${ }^{3}$ and R. Domínguez-Gómez ${ }^{4}$ \\ Received 2004 August 31; accepted 2005 March 9
}

\begin{abstract}
The molecular structure of methyl formate is determined from ab initio calculations. The molecule presents two conformers (cis and trans) with a $5.3 \mathrm{kcal} \mathrm{mol}^{-1}$ difference in energy. In the most stable cis conformer, the carbonyl group eclipses the methyl group. The internal rotation barriers are $V_{3}(\mathrm{cis})=368 \mathrm{~cm}^{-1}$ and $V_{3}(\operatorname{trans})=26 \mathrm{~cm}^{-1}$ for the methyl group and $V^{\mathrm{CO}}=4826 \mathrm{~cm}^{-1}$ for the $\mathrm{CO}$ group. The dependence of the spectroscopic parameters on the torsional motions is detailed. The rotational-torsional energy levels have been calculated variationally up to $J=6$ using a flexible model depending on the two torsional modes. Far-infrared frequencies and intensities are determined at room temperature. The rotational parameters have been computed to be $A=20,040.473 \mathrm{MHz}, B=6974.140 \mathrm{MHz}$, $C=5350.705 \mathrm{MHz}, D_{J}=-0.510 \mathrm{kHz}, D_{J K}=1.566 \mathrm{kHz}$, and $D_{K}=-0.619 \mathrm{kHz}$; and $A=20,040.492 \mathrm{MHz}$, $B=6974.399 \mathrm{MHz}, C=5350.851 \mathrm{MHz}, D_{J}=2.070 \mathrm{kHz}, D_{J K}=14.712 \mathrm{kHz}$, and $D_{K}=5.898 \mathrm{kHz}$ at the symmetric and $E$ components of the cis ground state, respectively. The corresponding values for trans-methyl formate are $A=47,380.066 \mathrm{MHz}, B=4738.781 \mathrm{MHz}$, and $C=4430.339 \mathrm{MHz}$; and $A=47,389.697 \mathrm{MHz}, B=4737.751 \mathrm{MHz}$, and $C=4429.607 \mathrm{MHz}$.
\end{abstract}

Subject headings: astrochemistry — molecular data

\section{INTRODUCTION}

Quantum mechanical calculations represent an efficient procedure for a better understanding of experimental problems and for predicting and confirming molecular properties. Hence, the fundamental purpose of two of our previous papers has been the interpretation of the vibrational and rotational spectra of two prebiotic species detected in the interstellar medium (ISM): acetic acid and glycolaldehyde (Senent 2001, 2004). Both molecules are isomers that obey the empirical formula $\mathrm{C}_{2} \mathrm{O}_{2} \mathrm{H}_{4}$ and show nonrigid properties that make the interpretation of the low-frequency spectra difficult. The discovery of glycolaldehyde (Hollis et al. 2000), the simplest monosaccharide, has been followed with great interest, given its biological importance.

The set of $\mathrm{C}_{2} \mathrm{O}_{2} \mathrm{H}_{4}$ isomers presents a third component of astrophysical interest, the methyl formate $\mathrm{H}-\mathrm{COOCH}_{3}$. Although it is not the most stable species of the set, it is the most abundant in the ISM and has been the first to be detected in emission toward Sgr B2 (Brown et al. 1975). It is generally accepted that most millimeter and submillimeter emission lines observed toward Orion arise from only three molecules: methyl formate, dimethyl ether, and methanol (Johansson et al. 1984; Sutton et al. 1985; Blake et al. 1988). All of them present at least a methyl group capable of internal rotation, which causes the splitting of the energy levels into nondegenerate $(A)$ and degenerate $(E$ or $G$ ) substates. Dimethyl ether and methanol have been objects of previous studies performed in our laboratory (Senent et al. 1995; Muñoz-Caro et al. 1997).

\footnotetext{
1 Departamento de Astrofísica Molecular e Infrarroja (DAMIR), Instituto de Estructura de la Materia, CSIC, Calle Serrano 121, 28006 Madrid, Spain; imts420@iem.cfmac.csic.es.

2 Departamento de Química, Universidad Autónoma Metropolitana-Iztapalapa, Purísima y Michoacan, s/n, CP 09340 Mexico DF, Mexico.

3 Laboratorio de Química Teórica, Departamento de Fisicoquímica, Facultad de Ciencias Químicas, Benemérita Universidad Autónoma de Puebla, Edificio 140, Ciudad Universitaria, Puebla, Puebla-72570, Mexico.

4 Departamento de Ingeniería Civil, Cátedra de Química, E. U. I. T. Obras Públicas, Universidad Politécnica de Madrid, Calle Alfonso XIII, 3-5, 28014 Madrid, Spain.
}

Given its astrophysical relevance, the study of methyl formate as an isolated molecule has attracted major attention. Many papers concerning the vibrational (Wilmshurst 1957; Fateley \& Miller 1961; Susi \& Zell 1963; Susi \& Scherer 1969; Blom \& Günthard 1981; Chao et al. 1986) and rotational spectra (Curl 1959; Bauder 1979; Demaison et al. 1983; Plummer et al. 1984, 1986, 1987; Nadgaran \& Baker 1995; Oesterling et al. 1995, 1999; Karakawa et al. 2001; Ogata et al. 2004) have been published. The molecular structure has been investigated using ab initio methods (John \& Radom 1977; Fausto \& Teixeira-Dias 1987; Hansen et al. 2000; Rocha et al. 2002; Good \& Francisco 2002; Francisco 2003) or electron diffraction techniques (Cradock \& Rankin 1980). However, many aspects concerning the interpretation of the rotational spectra and formation at low pressures and temperatures in the ISM remain misinterpreted. For example, although it is generally accepted that methyl formate can be produced from the methanol formed in the ice of interstellar grains, detailed studies of the ion-molecule processes using experimental and theoretical methods are unable to account for the full number of spectral lines observed (Herbst \& Roberts 2004). Recently, a complete experimental and theoretical gas-phase study of methyl formate formation has been published (Horn et al. 2004).

The assignments of methyl formate vibrational and rotational spectra have special difficulties given the splitting of the levels caused by the two internal rotations. The first assignment of the methyl formate vibrational spectrum was performed in 1957 (Wilmshurst 1957). In this case, the two torsional modes were neglected in the study. Later, Fateley \& Miller (1961) located the torsional methyl group at $130 \mathrm{~cm}^{-1}$. It is well known that the molecule presents two different conformers. From low-temperature Ar matrix infrared spectroscopy, the energy difference between stable geometries, $\Delta H$, has been determined to be $4.750 \pm$ $0.190 \mathrm{kcal} \mathrm{mol}^{-1}$, and some observed bands have been assigned to the unstable trans conformer (Blom \& Günthard 1981). Fundamental frequencies from Chao et al. (1986) are collected in the BASEMOL database (Crovisier 2002).

Many aspects related to the assignments of the millimeter and submillimeter lines of methyl formate remain incomplete. For 
example, more or less complex global fits of lines corresponding to the $A$ and $E$ components of the ground and first excited states lead to quite different spectroscopic parameters. This disagreement is related to the most important spectroscopic parameters, the rotational constants, which are directly related to the molecular structure. Although there is an acceptable agreement for the "out-of-plane" $C$ constant, different authors provide quite different "in-plane" constants. For example, the values of $A$ and $B$ of Demaison et al. (1983; 19,983.055 and 6914.4198 MHz), Plummer et al. (1986; 19,980.3907 and 6913.6822 MHz), Nadgaran \& Baker (1995; 19,983 and 6914.928 MHz), Oesterling et al. (1999; 17,522.36993 and 9323.547665 MHz), Karakawa et al. $(2001 ; 19,141.92$ and $9112.39 \mathrm{MHz})$, and Ogata et al. (2004; 19,120.151 and 9181.7185 MHz) are not consistent. The BASEMOL (Crovisier 2002) database collects the results of Oesterling et al. (1999), who have also analyzed the deuterated isotopic variety $\mathrm{D}-\mathrm{COOCH}_{3}$ (Oesterling et al. 1995). Ab initio calculations can be a complementary technique in the molecular structure determination and for understanding the experimental results.

To our knowledge, accurate ab initio data capable of clarifying the rotational observations are not available. The relative energies and structures of the conformers published in the earlier ab initio studies (John \& Radom 1977; Fausto \& Teixeira-Dias 1987) were determined with methods unsuitable for a rotational analysis. Recent high-level calculations are limited to the determination of the cis structure and the vertical excitations (Hansen et al. 2000; Rocha et al. 2002; Good \& Francisco 2002; Francisco 2003).

Thus, the main object of this paper is to obtain as much information as possible concerning structure and spectroscopic properties that can be derived from ab initio calculations. We analyzed the spectra from a two-dimensional flexible model depending on the modes responsible for the nonrigidity of the molecule. The potential energy surface and the parameters of the Hamiltonian are determined from ab initio energies and geometries. A final fit using the rovibrational energy levels allows us to determine rotational parameters corresponding to the vibrational energies, which are comparable with those obtained experimentally. The model has been previously tested

TABLE 1

Structural Parameters of Methyl Formate Conformers

\begin{tabular}{|c|c|c|}
\hline Parameter & Cis & Trans \\
\hline $\mathrm{C} 2 \mathrm{O} 1 \ldots$. & 1.3370 & 1.3442 \\
\hline $\mathrm{C} 3 \mathrm{O} 1 \ldots \ldots \ldots$ & 1.4344 & 1.4255 \\
\hline 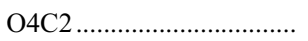 & 1.2035 & 1.1963 \\
\hline $\mathrm{H} 5 \mathrm{C} 2$ & 1.0922 & 1.0100 \\
\hline 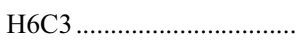 & 1.0817 & 1.0883 \\
\hline 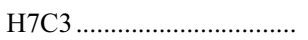 & 1.0851 & 1.0845 \\
\hline 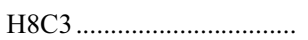 & 1.0851 & 1.0845 \\
\hline 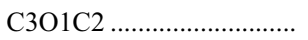 & 114.0 & 117.1 \\
\hline $\mathrm{O} 4 \mathrm{C} 2 \mathrm{O} 1$ & 125.6 & 122.9 \\
\hline 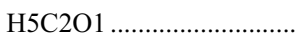 & 109.2 & 112.9 \\
\hline 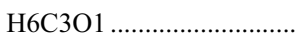 & 105.5 & 111.3 \\
\hline 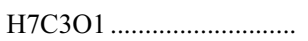 & 110.3 & 108.5 \\
\hline 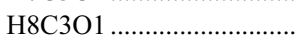 & 110.3 & 108.5 \\
\hline $\mathrm{O} 4 \mathrm{C} 2 \mathrm{O} 1 \mathrm{C} 3$ & 0.0 & 180.0 \\
\hline $\mathrm{H} 5 \mathrm{C} 2 \mathrm{O} 1 \mathrm{O} 4$ & 180.0 & 180.0 \\
\hline 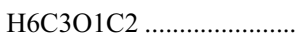 & 180.0 & 0.0 \\
\hline 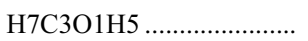 & 119.7 & 120.4 \\
\hline 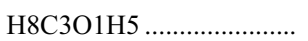 & -119.7 & -120.4 \\
\hline
\end{tabular}

Note.-Distances are in $\AA$, and angles are in degrees.

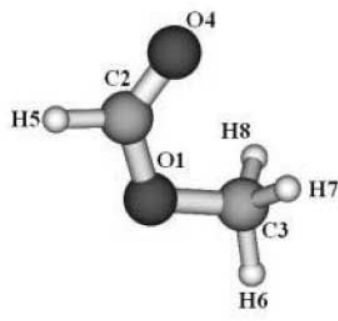

cis

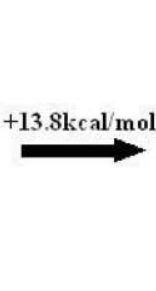

trans

$(\mathrm{E}=5.3 \mathrm{kcal} / \mathrm{mol})$

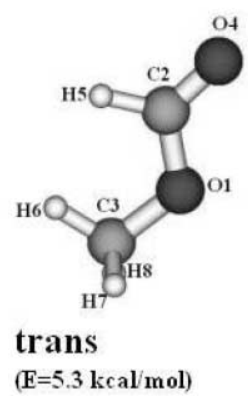

FIG. 1.-Two conformers of methyl formate.

for acetic acid (Senent 2001) and glycolaldehyde (Senent 2004).

\section{COMPUTATIONAL DETAILS}

All the calculations have been performed with Gaussian 03 (Frisch et al. 2004). The methyl formate potential energy surface has been determined with MP4(SDTQ)/cc-pVQZ ab initio calculations. The geometries of all the conformations have been optimized at the MP2/cc-pVQZ level. Fundamental frequencies have been computed at the MP2/cc-pVTZ level with the algorithm implemented in Gaussian 03 (Frisch et al. 2004). The torsional levels have been calculated variationally using a flexible two-dimensional model depending on the two torsional angles. The kinetic energy parameters of the Hamiltonian have been computed with the code MATRIZG.f (Senent 1998a) from the optimized geometries. The program BIDIM.f, designed for the study of the ethanol far-infrared spectrum (Senent et al. 2000), and the subroutines constructed for the study of the overall rotation of acetic acid (Senent 2001) have been employed for the determination of rovibrational energy levels and rotational parameters. Integral elements for the top symmetric functions are defined in Senent (1998b).

\section{THE MOLECULAR STRUCTURE OF METHYL FORMATE}

Methyl formate shows two planar conformations, cis and trans, of minimum energy, for which structural parameters are shown in Table 1. The terms cis and trans refer to the relative positions of the carbonyl and methyl groups (see Fig. 1). Both conformers are planar.

In the most stable cis geometry, the carbonyl group eclipses the methyl group. The methyl group is rotated in order to minimize the electrostatic repulsion responsible for the energy difference between conformers.

Two large-amplitude vibrations cause the nonrigid properties of methyl formate: the methyl group torsion and the $\mathrm{OC}-\mathrm{OC}$ central bond torsion. The corresponding coordinates are represented by the symbols $\theta$ and $\alpha$, which can be identified with the $\mathrm{H} 6 \mathrm{C} 3 \mathrm{O} 1 \mathrm{C} 2$ and $\mathrm{O} 4 \mathrm{C} 2 \mathrm{O} 1 \mathrm{C} 3$ dihedral angles (see Fig. 1). Their values at the cis and trans conformers are $\left(180^{\circ}, 0^{\circ}\right)$ and $\left(0^{\circ}\right.$, $\left.180^{\circ}\right)$, respectively. The central bond torsion produces the secondary minimum, for which the relative energy has been calculated to be $5.3 \mathrm{kcal} \mathrm{mol}^{-1}$ with MP4(SDTQ)/cc-pVQZ. The electrostatic potential maps (see Fig. 2) allow us to understand the enthalpy difference between conformers, which is in good agreement with the experimental value of Blom \& Günthard (1981; $4.8 \mathrm{kcal} \mathrm{mol}^{-1}$ ) obtained from the IR bands in an Ar matrix. The cis $\rightarrow$ trans transformation is hindered by a barrier 


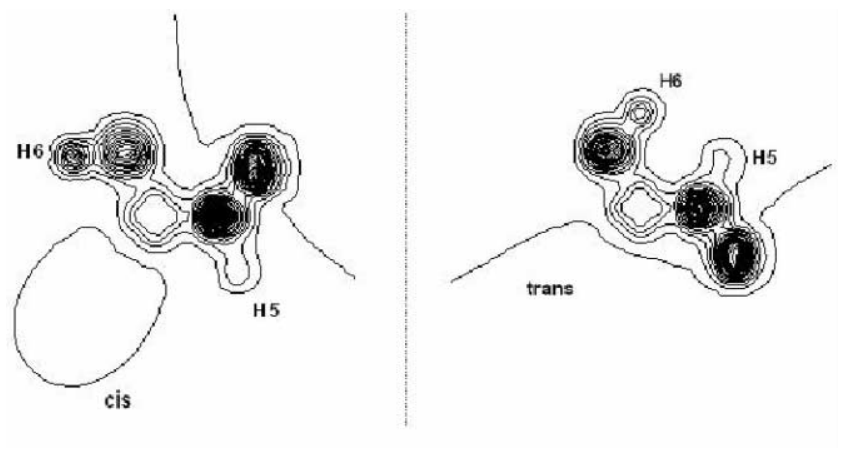

FIG. 2.-Electrostatic potential maps of cis- and trans-methyl formate.

calculated to be $13.8 \mathrm{kcal} \mathrm{mol}^{-1}$. The process occurs with a slight variation of the internuclear distances.

Table 2 shows some structural parameters of the two conformers, the barriers that hinder the internal rotations, and the most important spectroscopic properties calculated in the potential energy surface wells. The MP2/cc-pVQZ rotational constants have been determined to be $19,945.037,7017.551$, and $5364.780 \mathrm{MHz}$ for cis-methyl formate and 48,356.903, 4702.403, and 4404.249 MHz for trans-methyl formate. For the cis form, the calculated dipole moment components with respect to the principal axis, $\mu_{a}=1.7437 \mathrm{D}$ and $\mu_{b}=0.9640 \mathrm{D}$, are in reasonable agreement with the experimental data (Bauder 1979; $\mu_{a}=1.63 \mathrm{D}$ and $\left.\mu_{b}=0.68 \mathrm{D}\right)$. The dipole moment depends strongly on the $\mathrm{OC}-\mathrm{OC}$ torsional coordinate, which should show the largest intensities in far-infrared bands. The rotational constants of Table 2 are not comparable with the experimental results, which are measured in the levels, not in the potential holes.

In Table 2, approximate one-dimensional internal barriers are shown. They have been calculated to be $V_{3}(\mathrm{cis})=368 \mathrm{~cm}^{-1}$, $V_{3}($ trans $)=26 \mathrm{~cm}^{-1}$, and $V^{\mathrm{CO}}=4826 \mathrm{~cm}^{-1}\left(13.8 \mathrm{kcal} \mathrm{mol}^{-1}\right)$ from the curves in Figures 3 and 4 . These figures show the onedimensional potential energy surfaces calculated by fitting the relative electronic energies of a set of conformations where

TABLE 2

Molecular Properties of Methyl Formate Conformers

\begin{tabular}{|c|c|c|}
\hline Property & Cis & Trans \\
\hline $\begin{array}{l}\text { Symmetry } \\
\mu(\mathrm{D})\end{array}$ & $\begin{array}{l}C_{s} \\
1.9924\end{array}$ & $\begin{array}{l}C_{s} \\
4.7053\end{array}$ \\
\hline \multicolumn{3}{|c|}{ Kinetic Energy Parameters } \\
\hline$A_{e}(\mathrm{MHz})$ & $19,945.0367$ & $48,356.9026$ \\
\hline 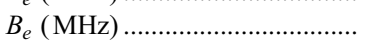 & 7017.5506 & 4702.4032 \\
\hline$C_{e}(\mathrm{MHz}) \ldots \ldots$ & 5364.7803 & 4404.2494 \\
\hline$\kappa$ & -0.77329 & -0.98643 \\
\hline$B_{11}\left(\mathrm{~cm}^{-1}\right) \ldots \ldots \ldots \ldots \ldots \ldots \ldots \ldots$ & 6.9948 & 7.1831 \\
\hline$B_{22}\left(\mathrm{~cm}^{-1}\right) \ldots \ldots \ldots \ldots \ldots \ldots \ldots \ldots \ldots \ldots \ldots \ldots \ldots$ & 5.7788 & 2.8895 \\
\hline$B_{12}\left(\mathrm{~cm}^{-1}\right) \ldots \ldots \ldots \ldots \ldots \ldots$ & -2.7498 & -0.4040 \\
\hline$V^{\prime}\left(\mathrm{cm}^{-1}\right) \ldots \ldots \ldots \ldots \ldots \ldots$ & 0.3412 & 0.2200 \\
\hline
\end{tabular}

Potential Energy Barriers $\left(\mathrm{cm}^{-1}\right)$

\begin{tabular}{|c|c|c|}
\hline $\mathrm{CH}_{3} \mathrm{Cis}$ & $\mathrm{CH}_{3}$ Trans & $\mathrm{C}-\mathrm{O}$ Cis $\rightarrow$ Trans \\
\hline $\begin{array}{l}V_{3}=368 \\
V_{3}^{\mathrm{ZVE}}=422\end{array}$ & $\begin{aligned} V_{3} & =26 \\
V_{3}^{\mathrm{ZPVE}} & =9\end{aligned}$ & $\begin{aligned} V^{\mathrm{CO}} & =4826 \\
V_{\mathrm{ZPVE}}^{\mathrm{CO}} & =4790\end{aligned}$ \\
\hline
\end{tabular}

Note.-Calculated with MP4(SDTQ)/cc-pVQZ//MP2/cc-pVQZ.

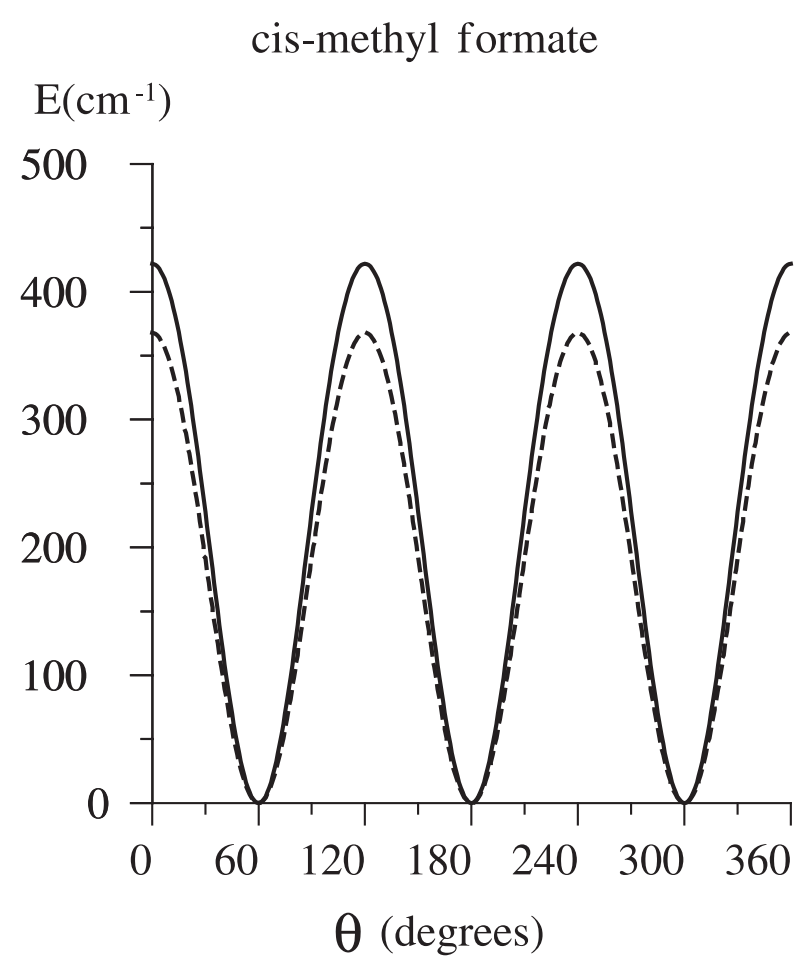

trans-methyl formate

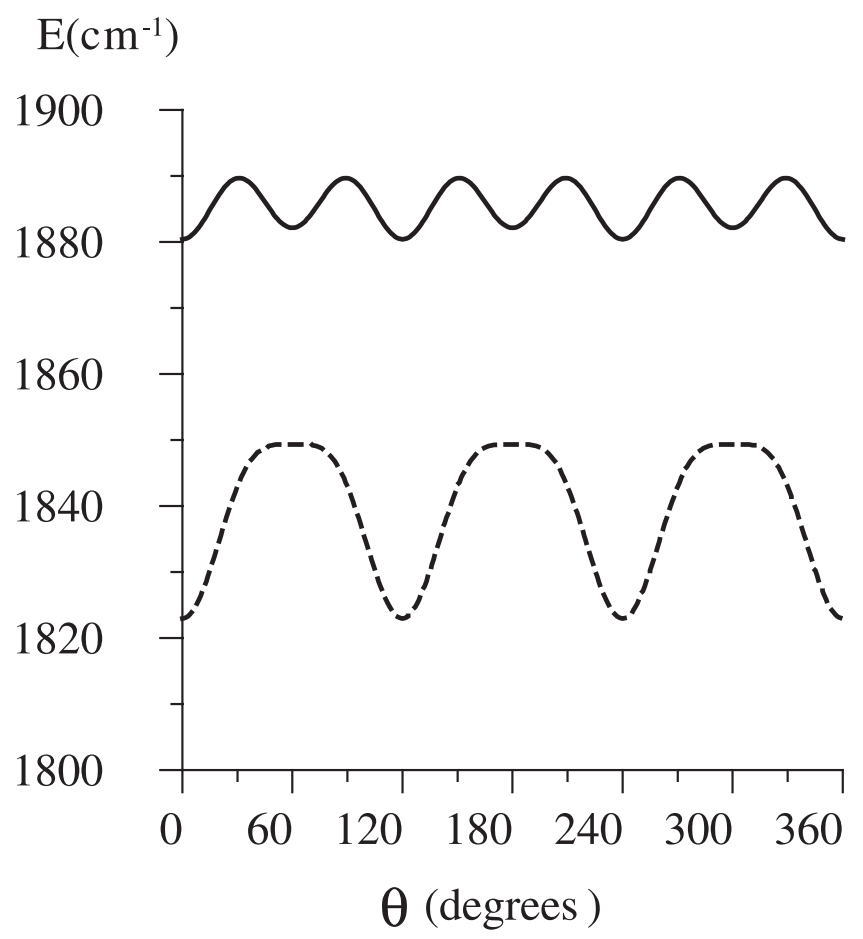

FIG. 3.-One-dimensional potential energy surfaces $V_{3}(\theta)$ for $c i s-$ and trans-methyl formate.

$3 N-7$ internal coordinates have been optimized. Dashed lines represent the potentials calculated from the total electronic energies, and the solid potentials comprise the zero-point vibrational correction (ZPVE). With these corrections, the barriers are $V_{3}$ (cis) $=422 \mathrm{~cm}^{-1}, V_{3}$ (trans) $=9 \mathrm{~cm}^{-1}$, and $V^{\mathrm{CO}}=4790 \mathrm{~cm}^{-1}$. For $V_{3}$ (cis), some experimental results arising from the fitting of 


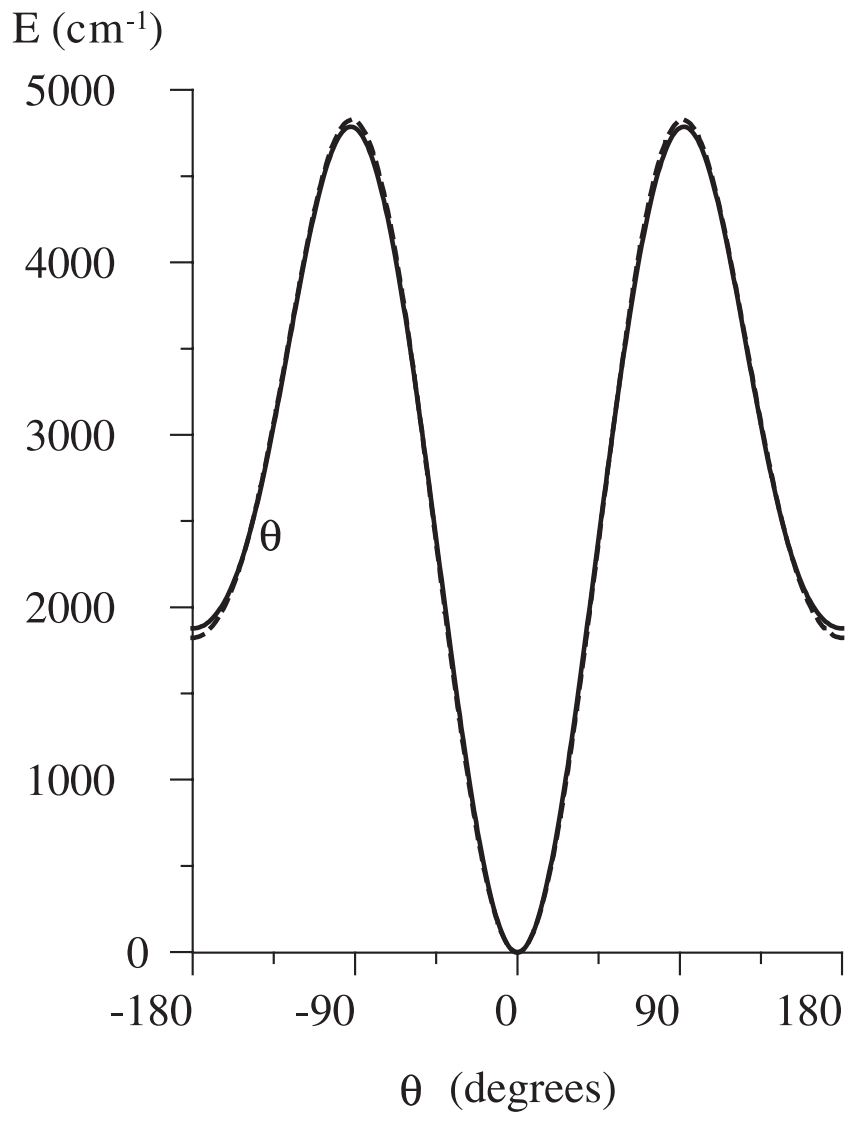

FIG. 4.-One-dimensional potential energy surface $V(\alpha)$ of methyl formate.

the millimeter and submillimeter observed lines are available in Oesterling et al. (1999; $\left.398.763 \mathrm{~cm}^{-1}\right)$, Karakawa et al. (2001; $\left.399.145 \mathrm{~cm}^{-1}\right)$, and Ogata et al. $\left(2004 ; 379.440 \mathrm{~cm}^{-1}\right)$. In this last paper, the term $V_{6}$ is also considered in the fitting.

\section{THE ROVIBRATIONAL SPECTRUM OF METHYL FORMATE}

\subsection{Theoretical Aspects}

The rotational-torsional energy levels are calculated variationally using the flexible model in two dimensions developed for the study of the far-infrared spectrum of acetic acid (Senent 2001). The Hamiltonian for $J=0$ can be identified with the pure torsional operator,

$$
\begin{aligned}
\hat{H}_{T}= & -\left(\frac{\partial}{\partial \theta}\right) B_{11}\left(\frac{\partial}{\partial \theta}\right)-\left(\frac{\partial}{\partial \theta}\right) B_{12}\left(\frac{\partial}{\partial \alpha}\right)-\left(\frac{\partial}{\partial \alpha}\right) B_{12}\left(\frac{\partial}{\partial \theta}\right) \\
& -\left(\frac{\partial}{\partial \alpha}\right) B_{22}\left(\frac{\partial}{\partial \alpha}\right)+V(\theta, \alpha)+V^{\prime}(\theta, \alpha)+V^{\mathrm{ZPVE}}(\theta, \alpha),
\end{aligned}
$$

where $V, V^{\prime}$, and $V^{\mathrm{ZPVE}}$ represent the potential energy surface, the pseudopotential, and the zero-point vibrational correction and $B_{11}, B_{22}$, and $B_{12}$ are the methyl torsion, the central bond torsion, and the torsion-torsion interaction kinetic energy parameters. They are related to the vibrational elements $g_{44}, g_{55}$, and $g_{45}$ of the $G$ matrix.

For each molecular structure, the kinetic parameters can be determined with our own algorithm (Senent 1998a). As all the parameters of the Hamiltonian transform as the totally sym- metric representation of the $C_{3 v}$ symmetry group, they can be described by $A_{1}$ double Fourier series. The torsional levels are calculated variationally using as a trial function a symmetryadapted double Fourier series. The convergence requires at least a Hamiltonian matrix with dimensions of $434\left(A_{1}\right), 433\left(A_{2}\right)$, $867\left(E_{x}\right)$, and $867\left(E_{y}\right)$.

Once the matrix is diagonalized, the most arduous effort is that of the classification of the energy levels, given the proximity of the two modes and the small gaps between splittings (Senent 2004). For this purpose, four criteria are considered: (1) the symmetry; (2) the values of the probability integrals around the minima, which allow one to distinguish between cis and trans levels; (3) the expectation values of the one-dimensional operators in the torsional levels, which allow one to assign the levels to each torsional mode; and (4) the intensities of the infrared transitions, which permit one to construct sequences of the levels.

The large difference between the oscillator strengths for the two modes permits one to use the infrared intensities for the assignments. The intensities of the $Q$ branches of the out-of-plane type $\mathrm{C}$ bands are calculated with

$$
I=\frac{q}{3 R^{2} e^{2} B} \omega\left(P_{j}-P_{i}\right)\left\langle\phi_{i}\left|\mu_{c}\right| \phi_{j}\right\rangle^{2}
$$

where $i$ and $j$ represent two connected states, $R$ is the average radius of the rotor, $B=\left(B_{11}+B_{22}\right)^{1 / 2}, \mu_{c}$ is the dipole moment component transforming as the $A_{2}$ representation, $P_{K}$ represents the Boltzmann population, $\omega$ is the frequency, and $q$ is the nuclear statistical weight. The selection rules are shown in the Appendix (Table A1). For methyl formate, the statistical weight ratio corresponding to the $A$ and $E$, nondegenerate and two-degenerate, representations of the $C_{3 v}$ group is $1: 1$.

For $J>0$, the ro-torsional Hamiltonian is written as the sum of the pure rotational Hamiltonian and the interaction operator, defined by

$$
\begin{aligned}
\hat{H}_{R}= & \sum_{\lambda=1}^{3} \sum_{\mu=1}^{3} g_{\lambda \mu} P_{\lambda} P_{\mu}, \quad \lambda, \mu=x, y, z, \\
\hat{H}_{R T}= & \frac{\hbar i}{2} \sum_{\lambda=1}^{3}\left[2 g_{\lambda 4}(\theta) P_{\lambda} \frac{\partial}{\partial \theta}-\left(\frac{\partial g_{\lambda 4}}{\partial \theta}\right) \frac{\partial}{\partial \lambda}\right. \\
& \left.+2 g_{\lambda 5}(\alpha) P_{\lambda} \frac{\partial}{\partial \alpha}\left(\frac{g_{\partial \lambda 5}}{\partial \alpha}\right) \frac{\partial}{\partial \lambda}\right],
\end{aligned}
$$

where $x, y$, and $z$ are the molecular Cartesian axes $A, B$, and $C$; $P_{\lambda}$ represents the angular momentum components; and $g_{\lambda \mu}$ and $g_{\lambda n}$ are the rotational and ro-torsional elements of the $G$ matrix (Senent 1998a). Following the principle axis method (PAM), the $g_{i j}$ elements for $i j=11,22,33,13,14,34,15$, and 35 transform as $A_{1}$, and those for $i j=12,23,15$, and 25 transform as $A_{2}$.

The rovibrational energy levels are calculated variationally. We use a contracted basis set to reduce the dimension of the Hamiltonian matrix, which factorizes in four boxes corresponding to the $A_{1}$, the $A_{2}$, and the $E$ two-degenerate representations (see the Appendix; Table A2). The contracted basis set may be a product of solutions of the vibrational Hamiltonian and solutions of the symmetric top in Cartesian coordinates (Senent 2001). Finally, the rotational parameters for the levels are evaluated by 
TABLE 3

Relative Electronic Energies ( $\mathrm{cm}^{-1}$ ) of the Selected Conformation of Methyl Formate

\begin{tabular}{|c|c|c|c|c|c|}
\hline $\begin{array}{c}\theta \\
(\operatorname{deg})\end{array}$ & $\begin{array}{c}\alpha \\
(\operatorname{deg})\end{array}$ & $E_{R}$ & $A$ & $B$ & $C$ \\
\hline \multirow[t]{3}{*}{$0 \ldots \ldots \ldots \ldots \ldots \ldots$} & 0 & 367.8 & $20,613.7$ & 6709.7 & 5228.5 \\
\hline & 90 & 191.7 & $20,297.6$ & 6844.4 & 5287.9 \\
\hline & 180 & $0.0^{\mathrm{a}}$ & $19,945.0$ & 7017.6 & 5364.8 \\
\hline \multirow[t]{4}{*}{$30 \ldots \ldots \ldots \ldots \ldots$} & 0 & 1383.0 & $21,114.9$ & 5201.5 & 6516.8 \\
\hline & 90 & 1315.2 & $21,039.2$ & 5213.4 & 6539.3 \\
\hline & 180 & 1199.7 & $20,680.9$ & 5279.7 & 6677.3 \\
\hline & -90 & 1270.1 & $20,749.2$ & 5267.7 & 6654.5 \\
\hline \multirow[t]{4}{*}{$60 \ldots \ldots \ldots \ldots$} & 0 & 3854.7 & $23,112.8$ & 5091.7 & 5951.4 \\
\hline & 90 & 3622.5 & $22,996.4$ & 5115.0 & 5984.1 \\
\hline & 180 & 3576.0 & $22,740.4$ & 5147.5 & 6038.0 \\
\hline & -90 & 3796.2 & $22,851.0$ & 5123.8 & 6003.7 \\
\hline \multirow[t]{4}{*}{$90 \ldots \ldots \ldots \ldots \ldots$} & 0 & 5421.5 & $26,794.1$ & 4996.5 & 5363.4 \\
\hline & 90 & 5117.1 & $26,653.1$ & 5023.0 & 5395.4 \\
\hline & 180 & 4822.1 & $26,238.6$ & 5076.3 & 5460.0 \\
\hline & -90 & 5087.0 & $26,366.6$ & 5051.0 & 5428.7 \\
\hline \multirow[t]{4}{*}{$120 \ldots \ldots \ldots \ldots$} & 0 & 4432.5 & $33,406.1$ & 4842.0 & 4935.7 \\
\hline & 90 & 4375.3 & $33,127.6$ & 4858.8 & 4957.6 \\
\hline & 180 & 3978.5 & $32,894.4$ & 4883.7 & 4991.7 \\
\hline & -90 & 4017.9 & $33,216.7$ & 4864.1 & 4965.3 \\
\hline \multirow[t]{4}{*}{$150 \ldots \ldots \ldots \ldots$} & 0 & 2617.5 & $43,100.4$ & 4518.8 & 4761.1 \\
\hline & 90 & 2716.4 & $42,445.3$ & 4536.4 & 4787.8 \\
\hline & 180 & 2501.5 & $42,108.5$ & 4553.1 & 4809.2 \\
\hline & -90 & 2414.0 & $42,781.5$ & 4533.8 & 4780.5 \\
\hline \multirow[t]{3}{*}{$180 \ldots \ldots \ldots \ldots$} & 0 & 1823.0 & $48,356.9$ & 4404.2 & 4702.4 \\
\hline & 90 & 1843.0 & $47,755.8$ & 4418.8 & 4724.3 \\
\hline & 180 & 1849.3 & $47,091.4$ & 4436.3 & 4750.5 \\
\hline
\end{tabular}

${ }^{\mathrm{a}} E_{\min }=-228.804898$ a.u. fitting the energies and the expectation values of the rotational Hamiltonian operators at the levels to

$$
\begin{aligned}
E & =\left\langle\psi_{i}\left|H_{\mathrm{ROT}}\right| \psi_{i}\right\rangle=\frac{1}{2}(B+C) J(J+1) \\
& +\left[A-\frac{1}{2}(B+C)\right]\left\langle\psi_{i}\left|\hat{J}_{z}^{2}\right| \psi_{i}\right\rangle-D_{J}[J(J+1)]^{2} \\
& -D_{J K} J(J+1)\left\langle\psi_{i}\left|\hat{J}_{z}^{2}\right| \psi_{i}\right\rangle-D_{K}\left\langle\psi_{i}\left|\hat{J}_{z}^{4}\right| \psi_{i}\right\rangle \\
& +H_{J}[J(J+1)]^{3}+H_{J K}[J(J+1)]^{2}\left\langle\psi_{i}\left|\hat{J}_{z}^{2}\right| \psi_{i}\right\rangle \\
& +H_{K J} J(J+1)\left\langle\psi_{i}\left|\hat{J}_{z}^{4}\right| \psi_{i}\right\rangle+H_{K}\left\langle\psi_{i}\left|\hat{J}_{z}^{6}\right| \psi_{i}\right\rangle \\
& +\frac{1}{4}(B-C)\left\langle\psi_{i}\left|\hat{J}_{+}^{2}+\hat{J}_{-}^{2}\right| \psi_{i}\right\rangle \\
& +\delta_{J} J(J+1)\left\langle\psi_{i}\left|\hat{J}_{+}^{2}+\hat{J}_{-}^{2}\right| \psi_{i}\right\rangle+\delta_{K}\left\langle\psi_{i}\left|\hat{J}_{+}^{4}+\hat{J}_{-}^{4}\right| \psi_{i}\right\rangle \\
& +\phi_{J}[J(J+1)]^{2}\left\langle\psi_{i}\left|\hat{J}_{+}^{2}+\hat{J}_{-}^{2}\right| \psi_{i}\right\rangle \\
& +\phi_{J K} J(J+1)\left\langle\psi_{i}\left|\hat{J}_{+}^{4}+\hat{J}_{-}^{4}\right| \psi_{i}\right\rangle+\phi_{K}\left\langle\psi_{i}\left|\hat{J}_{+}^{6}+\hat{J}_{-}^{6}\right| \psi_{i}\right\rangle .
\end{aligned}
$$

\subsection{The Far-Infrared Spectrum of Methyl Formate}

The far-infrared transitions of methyl formate have been calculated by solving variationally the Hamiltonian of equation (1). The kinetic and potential parameters are determined using ab initio calculations on a set of selected conformations (see Table 3), for which geometries have been computed optimizing $3 N-8$ parameters. In Tables 4, 5, and 6, the harmonic and anharmonic

\begin{tabular}{|c|c|c|c|c|c|c|c|}
\hline \multirow[b]{3}{*}{ AssignMENT } & \multicolumn{4}{|c|}{ CIS } & \multicolumn{3}{|c|}{ Trans } \\
\hline & \multicolumn{2}{|c|}{$\mathrm{HCO}_{2} \mathrm{CH}_{3}$} & \multirow{2}{*}{$\frac{\mathrm{HCO}_{2} \mathrm{CD}_{3}}{\text { Harmonic }}$} & \multirow{2}{*}{$\frac{\mathrm{DCO}_{2} \mathrm{CH}_{3}}{\text { Harmonic }}$} & \multirow{2}{*}{$\frac{\mathrm{HCO}_{2} \mathrm{CH}_{3}}{\text { Harmonic }}$} & \multirow{2}{*}{$\frac{\mathrm{HCO}_{2} \mathrm{CD}_{3}}{\text { Harmonic }}$} & \multirow{2}{*}{$\frac{\mathrm{DCO}_{2} \mathrm{CH}_{3}}{\text { Harmonic }}$} \\
\hline & Anharmonic & Experimental $^{\mathrm{a}}$ & & & & & \\
\hline \multicolumn{8}{|c|}{$A_{1}$} \\
\hline 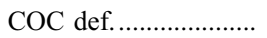 & 349 & 318 & 285 & 309 & 389 & 359 & 381 \\
\hline 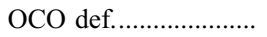 & 767 & 767 & 723 & 770 & 647 & 627 & 643 \\
\hline $\mathrm{O}-\mathrm{CH}_{3}$ st. $\ldots \ldots \ldots \ldots \ldots$ & 938 & 924 & 907 & 912 & 1049 & 901 & 1006 \\
\hline 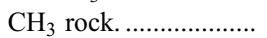 & 1167 & 1166 & 723 & 1080 & 1140 & 1023 & 1070 \\
\hline 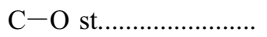 & 1213 & 1207 & 1002 & 1192 & 1285 & 1109 & 1149 \\
\hline 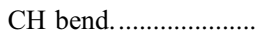 & 1380 & 1371 & 1093 & 1248 & 1423 & 1153 & 1280 \\
\hline 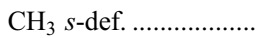 & 1446 & 1445 & 1134 & 1478 & 1500 & 1241 & 1493 \\
\hline 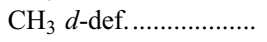 & 1480 & 1454 & 1250 & 1521 & 1538 & 1432 & 1537 \\
\hline $\mathrm{C}=\mathrm{O}$ st. $\ldots \ldots \ldots \ldots \ldots \ldots \ldots \ldots \ldots \ldots \ldots$ & 1762 & 1754 & 1409 & 1766 & 1829 & 1828 & 1800 \\
\hline 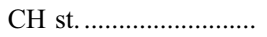 & 3007 & 2943 & 1790 & 2311 & 3016 & 2208 & 2241 \\
\hline $\mathrm{CH}_{3} s$-st....................... & 2959 & 2969 & 2221 & 3101 & 3081 & 2355 & 3080 \\
\hline $\mathrm{CH}_{3} d$-st. ...................... & 3090 & 3045 & 2398 & 3229 & 3176 & 3016 & 3176 \\
\hline \multicolumn{8}{|c|}{$A_{2}$} \\
\hline 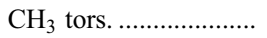 & 140 & 130 & 108 & 147 & 18 & 14 & 18 \\
\hline 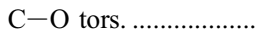 & 335 & 332 & 335 & 307 & 191 & 182 & 177 \\
\hline $\mathrm{CH}$ bend........................ & 1032 & 1032 & 926 & 893 & 1041 & 919 & 881 \\
\hline 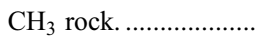 & 1168 & 1168 & 1055 & 1192 & 1193 & 1041 & 1193 \\
\hline 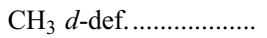 & 1466 & 1443 & 1089 & 1508 & 1507 & 1088 & 1507 \\
\hline 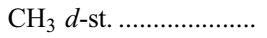 & 3054 & 3012 & 2371 & 3193 & 3196 & 2373 & 3196 \\
\hline ZPVE....................... & 13376 & 13240 & 11602 & 13078 & 13609 & 11435 & 12914 \\
\hline
\end{tabular}
frequencies, the torsional levels, and the frequencies and intensities of methyl formate are shown.

The frequencies of some isotopic varieties of methyl formate have been calculated from the MP2/cc-pVTZ force field (see Table 2). We initiate the study of methyl formate spectra from a harmonic analysis for three reasons: first, the harmonic fundamentals

TABLE 4

Fundamental Frequencies (in $\mathrm{cm}^{-1}$ ) of Some Methyl Formate Isotopes Calculated with MP2/cc-pVTZ

${ }^{\text {a }}$ Chao et al. (1986). 
TABLE 5

Torsional Energy Levels $\left(\mathrm{IN}^{-1}\right.$ )

\begin{tabular}{|c|c|c|c|c|c|c|c|c|}
\hline \multirow[b]{2}{*}{$v v^{\prime}$} & \multirow[b]{2}{*}{ SYMmEtRY } & \multicolumn{4}{|c|}{ Cis } & \multicolumn{3}{|c|}{ Trans } \\
\hline & & $2 \mathrm{D}$ & $+\mathrm{ZPVE}$ & Experimental $^{\mathrm{a}}$ & $1 \mathrm{D}$ & $2 \mathrm{D}$ & $+\mathrm{ZPVE}$ & $1 \mathrm{D}$ \\
\hline \multirow[t]{2}{*}{ 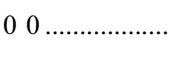 } & $A_{1}$ & $0^{\mathrm{b}}$ & $0^{\mathrm{c}}$ & $\ldots$ & 0 & $0^{\mathrm{d}}$ & $0^{\mathrm{e}}$ & 0 \\
\hline & $E$ & 0 & 0 & $\ldots$ & 0 & 6.3 & 7.0 & 6.1 \\
\hline \multirow[t]{2}{*}{$10 \ldots \ldots \ldots \ldots \ldots}$. & $A_{2}$ & 123.6 & 134.8 & 130 & 126.1 & 61.3 & 61.8 & 64.6 \\
\hline & $\mathrm{E}$ & 122.8 & 134.3 & $\ldots$ & 125.1 & 29.6 & 20.8 & 31.4 \\
\hline \multirow[t]{2}{*}{$20 \ldots \ldots \ldots \ldots \ldots$} & $A_{1}$ & 219.9 & 242.8 & $\ldots$ & 225.4 & 65.6 & 63.0 & 66.6 \\
\hline & $E$ & 228.0 & 248.9 & $\ldots$ & 233.0 & 111.1 & 110.0 & 115.0 \\
\hline \multirow[t]{2}{*}{$30 \ldots \ldots \ldots \ldots \ldots$} & $A_{2}$ & 334.1 & 358.0 & $\ldots$ & 339.6 & $\ldots$ & $\ldots$ & $\ldots$ \\
\hline & $E$ & 293.7 & 322.4 & $\ldots$ & 300.8 & $\ldots$ & $\ldots$ & $\ldots$ \\
\hline \multirow{2}{*}{ 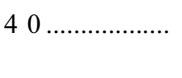 } & $A_{1}$ & 349.6 & 378.8 & $\ldots$ & 356.8 & $\ldots$ & $\ldots$ & $\ldots$ \\
\hline & $E$ & 409.3 & 434.6 & $\ldots$ & 415.8 & $\ldots$ & $\ldots$ & $\ldots$ \\
\hline \multirow{2}{*}{$01 \ldots \ldots \ldots \ldots \ldots$} & $A_{2}$ & 321.7 & 329.5 & 332 & 294.2 & 181.5 & 177.1 & 148.3 \\
\hline & $E$ & 321.9 & 330.3 & $\ldots$ & $\ldots$ & 187.1 & 184.9 & $\ldots$ \\
\hline \multirow[t]{2}{*}{$02 \ldots \ldots \ldots \ldots \ldots \ldots$} & $A_{1}$ & 634.8 & 648.4 & $\ldots$ & 581.1 & $\ldots$ & $\ldots$ & $\ldots$ \\
\hline & $E$ & 635.3 & 649.1 & $\ldots$ & $\ldots$ & $\ldots$ & $\ldots$ & $\ldots$ \\
\hline \multirow[t]{2}{*}{$03 \ldots \ldots \ldots \ldots \ldots \ldots$} & $A_{2}$ & 939.8 & 957.2 & $\ldots$ & 860.8 & $\ldots$ & $\ldots$ & $\ldots$ \\
\hline & $E$ & 940.4 & 958.0 & $\ldots$ & $\ldots$ & $\ldots$ & $\ldots$ & $\ldots$ \\
\hline \multirow[t]{2}{*}{$11 \ldots \ldots \ldots \ldots \ldots$} & $A_{1}$ & 440.8 & 457.4 & $\ldots$ & $\ldots$ & $\ldots$ & $\ldots$ & $\ldots$ \\
\hline & $E$ & 439.9 & 456.9 & $\ldots$ & $\ldots$ & $\ldots$ & $\ldots$ & $\ldots$ \\
\hline \multirow[t]{2}{*}{$12 \ldots \ldots \ldots \ldots \ldots$} & $A_{2}$ & 531.2 & 608.4 & $\cdots$ & $\cdots$ & $\cdots$ & $\cdots$ & $\ldots$ \\
\hline & $E$ & 540.8 & 564.5 & $\ldots$ & $\ldots$ & $\ldots$ & $\ldots$ & $\ldots$ \\
\hline \multirow[t]{2}{*}{$21 \ldots \ldots \ldots \ldots \ldots . .}$. & $A_{2}$ & 749.8 & 770.0 & $\ldots$ & $\ldots$ & $\ldots$ & $\ldots$ & $\ldots$ \\
\hline & $E$ & 748.6 & 769.3 & $\ldots$ & $\ldots$ & $\ldots$ & $\ldots$ & $\ldots$ \\
\hline
\end{tabular}

${ }^{\text {a }}$ Chao et al. (1986).

b $228.8 \mathrm{~cm}^{-1}$

c $240.2 \mathrm{~cm}^{-1}$.

d $1924.8 \mathrm{~cm}^{-1}$.

e $1969.3 \mathrm{~cm}^{-1}$.

represent preliminary frequencies; second, they allow one to distinguish the minima and the saddle points of the potential energy curves; and third, they allow one to predict the strength of the interactions among modes. The deuterated forms ensure the correct assignment. In the case of the most stable conformer, anharmonic frequencies are also calculated using perturbation theory. For some medium- and small-amplitude modes, the agreement between anharmonic frequencies and experimental values is quite good. In all the cases, the accuracy is reasonable for the level of ab initio calculations that we have used. The anharmonic

TABLE 6

Predicted Far-Infrared Frequencies $\left(\mathrm{In} \mathrm{cm}^{-1}\right.$ ) and Absolute Intensities for Cis and Trans Methyl Formate Calculated at $273.15 \mathrm{~K}$

\begin{tabular}{|c|c|c|c|c|c|c|c|}
\hline \multirow[b]{2}{*}{$v_{i} v_{i}^{\prime} \rightarrow v_{j} v_{j}^{\prime}$} & \multirow[b]{2}{*}{ SYMMETRY } & \multicolumn{3}{|c|}{ Cis } & \multicolumn{3}{|c|}{ Trans } \\
\hline & & Variational Frequency & Intensity & $\nu_{18}$ Perturbation Theory & Variational Frequency & Intensity & $\omega_{17}$ \\
\hline \multicolumn{8}{|c|}{$\mathrm{CH}_{3}$} \\
\hline \multirow{2}{*}{$00 \rightarrow 10$} & $A_{1} \rightarrow A_{2}$ & 134.8 & $0.626 \times 10^{-6}$ & 140 & 61.8 & $0.928 \times 10^{-10}$ & 18 \\
\hline & $E \rightarrow E$ & 134.3 & $0.609 \times 10^{-6}$ & $\ldots$ & 20.8 & $0.031 \times 10^{-10}$ & $\ldots$ \\
\hline $10 \rightarrow 20 \ldots \ldots \ldots \ldots$ & $A_{2} \rightarrow A_{1}$ & 108.0 & $0.054 \times 10^{-6}$ & 87 & $\ldots$ & $\ldots$ & $\ldots$ \\
\hline \multicolumn{8}{|c|}{$\mathrm{OC}-\mathrm{OC}$} \\
\hline \multirow[t]{2}{*}{$00 \rightarrow 01 \ldots \ldots \ldots \ldots$} & $A_{1} \rightarrow A_{2}$ & 329.5 & 0.0118 & 335 & 177.1 & $0.274 \times 10^{-7}$ & 191 \\
\hline & $E \rightarrow E$ & 330.3 & 0.0111 & $\ldots$ & 177.9 & $0.261 \times 10^{-} 7$ & $\ldots$ \\
\hline \multirow[t]{2}{*}{$01 \rightarrow 02 \ldots \ldots \ldots \ldots$} & $A_{2} \rightarrow A_{1}$ & 318.9 & 0.0039 & 331 & $\ldots$ & $\ldots$ & $\ldots$ \\
\hline & $E \rightarrow E$ & 318.8 & 0.0039 & $\ldots$ & $\ldots$ & $\ldots$ & $\ldots$ \\
\hline $01 \rightarrow 11 \ldots \ldots \ldots \ldots$ & $E \rightarrow E$ & 126.6 & $0.744 \times 10^{-7}$ & $\ldots$ & $\ldots$ & $\ldots$ & $\ldots$ \\
\hline \multirow[t]{2}{*}{$11 \rightarrow 21 \ldots \ldots \ldots$} & $A_{1} \rightarrow A_{2}$ & 151.0 & $0.727 \times 10^{-7}$ & $\ldots$ & $\ldots$ & $\ldots$ & $\ldots$ \\
\hline & $E \rightarrow E$ & 107.6 & $0.016 \times 10^{-7}$ & $\ldots$ & $\ldots$ & $\ldots$ & $\ldots$ \\
\hline \multirow[t]{2}{*}{$11 \rightarrow 12 \ldots \ldots \ldots$} & $A_{1} \rightarrow A_{2}$ & 312.6 & 0.0020 & $\ldots$ & $\ldots$ & $\ldots$ & $\ldots$ \\
\hline & $E \rightarrow E$ & 312.4 & 0.0020 & $\ldots$ & $\ldots$ & $\ldots$ & $\ldots$ \\
\hline
\end{tabular}




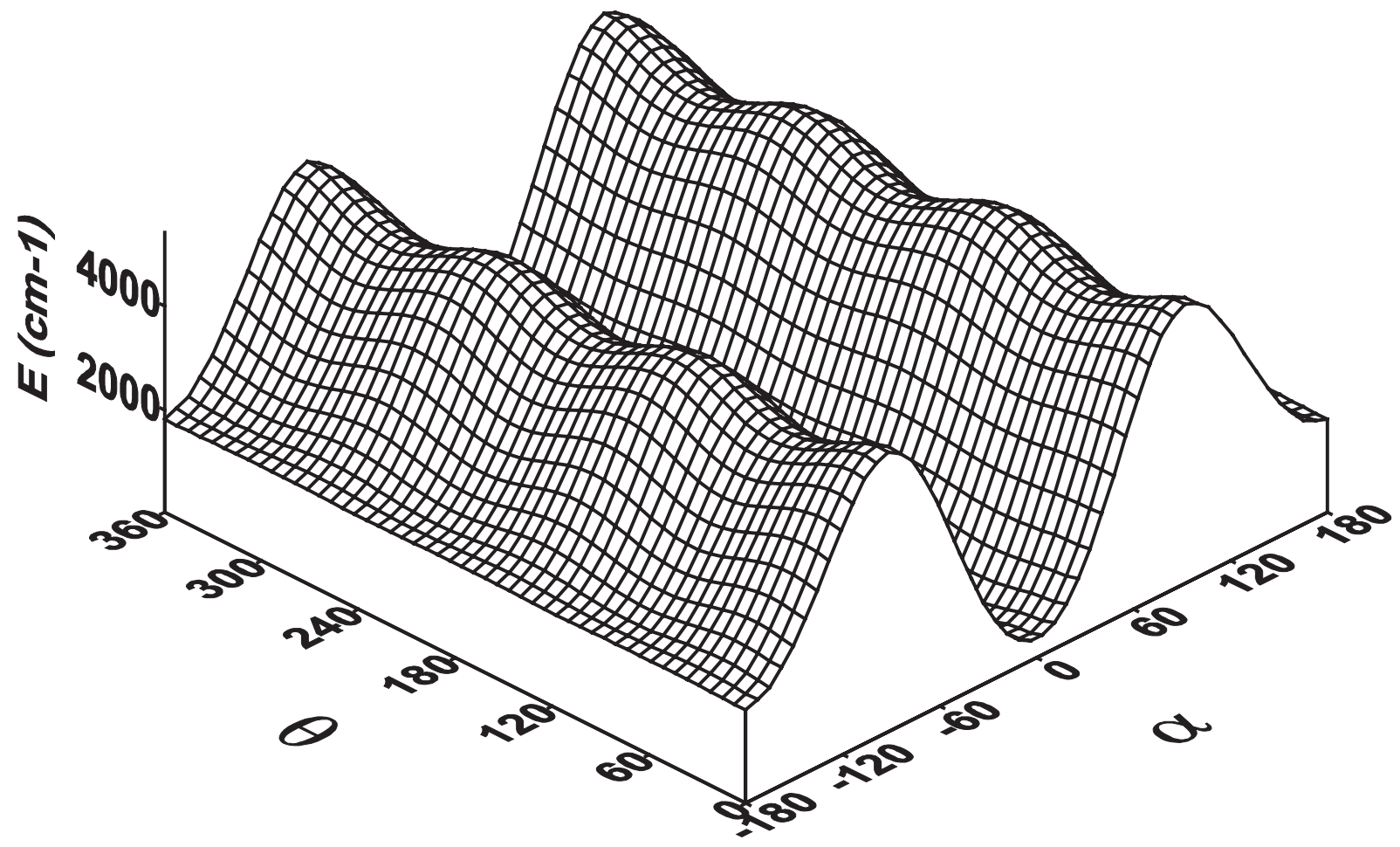

FIG. 5.-Two-dimensional potential energy surface of methyl formate.

fundamentals of the two torsional modes have been determined to be 140 and $335 \mathrm{~cm}^{-1}$ for the cis form, and the harmonic fundamentals, to be 18 and $191 \mathrm{~cm}^{-1}$ for the trans form. Experimental cis values are 130 and $332 \mathrm{~cm}^{-1}$. By regarding the energy and symmetry of the modes, one may expect the presence of Fermi interactions between the cis $A_{1}$ COC deformation mode $\left(348 \mathrm{~cm}^{-1}\right)$ and the cis $\mathrm{CH}_{3}$ torsion overtone $\left(140 \times 2=280 \mathrm{~cm}^{-1}\right)$, and between the trans $A_{1}$ COC deformation mode $\left(389 \mathrm{~cm}^{-1}\right)$ and the trans central bond torsion overtone $\left(191 \times 2=382 \mathrm{~cm}^{-1}\right)$.

These torsional fundamentals represent a first approximation. The methods implemented in Gaussian 03 have been developed for semirigid molecules showing a single minimum. Nonrigid molecules show various minima separated by barriers that produce the splitting of the levels by tunnelling. For this reason, the determination of realistic torsional energies implies the consideration of all the minima. The potential energy surface is shown in Figure 5. It has been determined by fitting to a double Fourier series the MP4(SDTQ)/cc-pVQZ relative energies of the set of 26 conformations selected (see Table 3). Then,

$$
\begin{aligned}
V(\theta, \alpha) & =2982.2-723.5 \cos (\alpha)-2042.6 \cos (2 \alpha) \\
& -112.4 \cos (3 \alpha)+80.6 \cos (4 \alpha)+10.0 \cos (5 \alpha) \\
& -6.5 \cos (6 \alpha)+150.2 \cos (3 \theta)+28.0 \cos (3 \theta) \cos (\alpha) \\
& -107.5 \cos (3 \theta) \cos (\alpha)+62.1 \cos (3 \theta) \cos (3 \alpha) \\
& +42.3 \cos (3 \theta) \cos (4 \alpha)+8.5 \cos (3 \theta) \cos (5 \alpha) \\
& +0.4 \cos (3 \theta) \cos (6 \alpha)+1.7 \cos (6 \theta) \\
& +0.3 \cos (6 \theta) \cos (\alpha)-6.3 \cos (6 \theta) \cos (2 \alpha) \\
& +0.4 \cos (6 \theta) \cos (3 \alpha)+1.4 \cos (6 \theta) \cos (4 \alpha) \\
& -1.0 \cos (6 \theta) \cos (5 \alpha)-0.4 \cos (6 \theta) \cos (6 \alpha) \\
& -60.5 \sin (3 \theta) \sin (\alpha)+113.8 \sin (3 \theta) \sin (2 \alpha) \\
& -52.9 \sin (3 \theta) \sin (3 \alpha)-39.5 \sin (3 \theta) \sin (4 \alpha) \\
& -7.5 \sin (3 \theta) \sin (5 \alpha) .
\end{aligned}
$$

The surface has been corrected by adding the zero-point vibrational correction calculated within the harmonic approximation at the MP4(SDQ)/cc-pVQZ level.

In molecules with hindered internal rotation, the methyl groups lose the "static" $C_{3 v}$ symmetry, in spite of the fact that the "dynamic" symmetry is preserved. This "symmetry dilemma" is evidenced during the geometry optimization, if a single internal coordinate is frozen. For example, if the $\mathrm{H} 6 \mathrm{C} 3 \mathrm{O} 1 \mathrm{C} 2$ dihedral angle is frozen at $\theta$, the resulting energy is different from the one obtained by freezing $\mathrm{H} 7 \mathrm{C} 3 \mathrm{O} 1 \mathrm{C} 2$ at $\theta+120^{\circ}$, or by freezing $\mathrm{H} 8 \mathrm{C} 3 \mathrm{O} 1 \mathrm{C} 2$ at $\theta-120^{\circ}$. In previous papers (Villa et al. 1999; Szalay et al. 2002), we have proposed two possible ways of minimizing or eliminating the numerical errors derived from the dilemma. The first is to select a set of conformations where one of the dihedral angles is fixed at $0^{\circ}, 180^{\circ}$, and $90^{\circ}$. Thus, one of the methyl $\mathrm{CH}$ bonds remains in the plane or perpendicular to the molecular plane. The second is to optimize the geometry by freezing the torsional coordinate defined as $\theta=1 / 3\left(\theta_{1}+\theta_{2}+\right.$ $\theta_{3}$ ). In this case, the remaining linear combinations of internal coordinates are allowed to be relaxed. In the case of applying this last solution in correlated calculations, it will be necessary to develop new ab initio software.

The torsional energy levels of Table 5 are classified using the four criteria described in the theoretical section of this paper. The calculations have been performed without considering the zero vibrational correction (2D) and including the zero-point vibrational correction (+ZPVE). As is well known, ZPVE is the most important correction in accurate calculations of vibrational levels in the case of reduced models. Nevertheless, the effect of the pseudopotential on the levels is negligible. The calculations have also been performed in one dimension (1D) using the potential energy surfaces presented in Figures 3 and 4. In principle, the one-dimensional results were considered for evaluating the interactions between the two torsions. They have been achieved neglecting the ZPVE corrections. 
TABLE 7

Rotational Levels (in $\mathrm{cm}^{-1}$ ) For the Two Components $A$ and $E$ of the Cis and the Trans Vibrational Ground States

\begin{tabular}{|c|c|c|c|c|}
\hline \multirow[b]{2}{*}{$J_{\left|K_{a}\right|\left|K_{c}\right|}$} & \multicolumn{2}{|c|}{ CIs } & \multicolumn{2}{|c|}{ Trans } \\
\hline & $A$ & E & $A$ & E \\
\hline $000 A_{1} \ldots \ldots \ldots \ldots \ldots$ & 0.000 & 0.012 & 1729.111 & 1736.061 \\
\hline $101 A_{2} \ldots \ldots \ldots \ldots \ldots \ldots \ldots$ & 0.411 & 0.424 & 1729.417 & 1736.367 \\
\hline $111 A_{2} \ldots \ldots \ldots \ldots \ldots \ldots \ldots$ & 0.847 & 0.859 & 1730.840 & 1737.789 \\
\hline $110 A_{1} \ldots \ldots \ldots \ldots \ldots \ldots \ldots$ & 0.901 & 0.913 & 1730.850 & 1737.800 \\
\hline $202 A_{1} \ldots \ldots \ldots \ldots \ldots \ldots \ldots \ldots \ldots$ & 1.229 & 1.241 & 1730.029 & 1736.978 \\
\hline $212 A_{1} \ldots \ldots \ldots \ldots \ldots \ldots \ldots \ldots$ & 1.615 & 1.627 & 1731.441 & 1738.391 \\
\hline $211 A_{2} \ldots \ldots \ldots \ldots \ldots \ldots$ & 1.778 & 1.790 & 1731.472 & 1738.421 \\
\hline $221 A_{2} \ldots \ldots \ldots \ldots \ldots \ldots \ldots$ & 3.085 & 3.096 & 1735.739 & 1742.690 \\
\hline $220 A_{1} \ldots \ldots \ldots \ldots \ldots \ldots \ldots$ & 3.090 & 3.102 & 1735.739 & 1742.690 \\
\hline $303 A_{2} \ldots \ldots \ldots \ldots \ldots \ldots \ldots \ldots$ & 2.439 & 2.453 & 1730.946 & 1737.895 \\
\hline $313 A_{2} \ldots \ldots \ldots \ldots \ldots \ldots \ldots \ldots \ldots$ & 2.767 & 2.777 & 1732.343 & 1739.293 \\
\hline $312 A_{1} \ldots \ldots \ldots \ldots \ldots \ldots \ldots \ldots$ & 3.089 & 3.101 & 1732.405 & 1739.354 \\
\hline $322 A_{1} \ldots \ldots \ldots \ldots \ldots \ldots \ldots$ & 4.319 & 4.330 & 1736.656 & 1743.607 \\
\hline 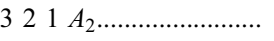 & 4.342 & 4.354 & 1736.656 & 1743.607 \\
\hline $331 A_{2} \ldots \ldots \ldots \ldots \ldots \ldots \ldots$ & 6.639 & 6.645 & 1743.794 & 1750.746 \\
\hline $330 A_{1} \ldots \ldots \ldots \ldots \ldots \ldots$ & 6.636 & 6.651 & 1734.794 & 1750.746 \\
\hline
\end{tabular}

The one-dimensional model appears to be very inefficient for the central bond torsion. For the methyl torsion, a displacement of $\sim 3 \mathrm{~cm}^{-1}$ up to the lower frequencies is observed when the one- and two-dimensional calculations are compared. The two-dimensional mode improves the calculations of the methyl band position. Furthermore, as was first observed for ethanol (Senent et al. 2000) and acetic acid (Senent 2001), the reduced model efficiency is always more evident on the higher frequency torsional mode.

The fundamental anharmonic frequencies of the methyl and central bond torsion of $c i s$-methyl formate have been computed to be $123.6(A)$ and $122.8 \mathrm{~cm}^{-1}(E)$ and to be $321.7(A)$ and $321.9 \mathrm{~cm}^{-1}(E)$, without the ZPVE, and considering the ZPVE they have been calculated at $134.8(A)$ and $134.3 \mathrm{~cm}^{-1}(E)$ and $329.5(A)$ and $330.2 \mathrm{~cm}^{-1}(E)$. These last calculations are in a very good agreement with the experimental values of $130\left(\mathrm{CH}_{3}\right)$ and $332 \mathrm{~cm}^{-1}$ (OC-OC; Chao et al. 1986). The difference of $\sim 4 \mathrm{~cm}^{-1}$ between the calculated and experimental values for the methyl group can arise from the way that the symmetry dilemma has been corrected.

All the calculated trans levels lie over the methyl torsional barrier. The ground states have been localized at 1924.8 (without the ZPVE correction) and $1969.3 \mathrm{~cm}^{-1}$ (with the ZPVE correction). They show two components, $A$ and $E$, separated by 6.3 and $7 \mathrm{~cm}^{-1}$. The assignment of these levels is especially arduous and has been performed with the help of one-dimensional results. The methyl torsion anharmonic fundamental has been found to lie at $61.8 \mathrm{~cm}^{-1}$, and the one for the central bond torsion at $177.1 \mathrm{~cm}^{-1}$. The harmonic frequencies are 18 and $191 \mathrm{~cm}^{-1}$ (see Table 4).

The frequencies and intensities of the transitions connecting the lowest levels are shown in Table 6. As was expected, the transitions assigned to $\mathrm{OC}-\mathrm{OC}$ are the strongest ones. The intensities are calculated at $273.15 \mathrm{~K}$. At very low temperatures $(\sim 20 \mathrm{~K})$, only the ground state of the cis conformer is populated.

\subsection{The Rotational Parameters of Methyl Formate}

The rovibrational levels for $J>0$ have been computed by solving variationally the Hamiltonian of equation (6). In Table 7, the rotational energies for the $A$ and $E$ substates of the cis and trans ground states are shown. By fitting to equation (5) the expectation values of the Watson Hamiltonian operators, the rotational parameters have been computed to be $A=20,040.473 \mathrm{MHz}$, $B=6974.140 \mathrm{MHz}, C=5350.705 \mathrm{MHz}, D_{J}=-0.510 \mathrm{kHz}$, $D_{J K}=1.566 \mathrm{kHz}$, and $D_{K}=-0.619 \mathrm{kHz} ;$ and $A=$ $20,040.492 \mathrm{MHz}, B=6974.399 \mathrm{MHz}, C=5350.851 \mathrm{MHz}$, $D_{J}=2.070 \mathrm{kHz}, D_{J K}=14.712 \mathrm{kHz}$, and $D_{K}=5.898 \mathrm{kHz}$ at the symmetric and $E$ components of the cis ground state,

TABLE 8

Computed Rotational Parameters of Cis- and Trans-Methyl Formate at the Lowest Torsional States

\begin{tabular}{|c|c|c|c|c|}
\hline \multirow{2}{*}{$\begin{array}{l}\text { Ground State } \\
\text { Cis }\left(\begin{array}{ll}0 & 0\end{array}\right)\end{array}$} & \multicolumn{2}{|c|}{$A$} & \multicolumn{2}{|c|}{$B$} \\
\hline & Calculated & Experimental $^{\mathrm{a}}$ & Calculated & Experimental $^{\mathrm{b}}$ \\
\hline$A(\mathrm{MHz}) \ldots \ldots$ & $20,040.473$ & $19,985.7623$ & $20,040.492$ & $19,980.3907$ \\
\hline B (MHz) & 6974.140 & 6914.7577 & 6974.399 & 6913.6822 \\
\hline$C(\mathrm{MHz})$ & 5350.851 & 5304.4681 & 5350.851 & 5304.5114 \\
\hline$D_{J}(\mathrm{kHz})$ & -0.510 & 6.1781 & 2.070 & 5.8895 \\
\hline$D_{J K}(\mathrm{kHz})$ & 1.566 & -17.1981 & 14.712 & -23.313 \\
\hline$D_{K}(\mathrm{kHz}) \ldots \ldots \ldots \ldots \ldots \ldots \ldots \ldots \ldots \ldots$ & -0.619 & 82.3578 & 5.898 & 75.4009 \\
\hline$\delta_{J}(\mathrm{kHz})$ & -0.237 & 1.9502 & -0.223 & 1.8571 \\
\hline \multirow[t]{2}{*}{$\delta_{J}(\mathrm{kHz})$} & -0.309 & 7.6605 & -1.554 & 2.057 \\
\hline & \multicolumn{2}{|c|}{ Cis $\left(\begin{array}{ll}1 & 0\end{array}\right)$} & \multicolumn{2}{|c|}{ Trans $\left(\begin{array}{ll}0 & 0\end{array}\right)$} \\
\hline Excited States & $A$ & E & $A$ & E \\
\hline$A(\mathrm{MHz}) \ldots \ldots \ldots$ & $20,164.023$ & $20,167.381$ & $47,380.066$ & $47,389.645$ \\
\hline B (MHz) & 6913.492 & 6911.891 & 4738.781 & 4737.653 \\
\hline $\mathrm{C}(\mathrm{MHz})$ & 5323.755 & 5323.043 & 4430.339 & 4429.715 \\
\hline$D_{J}(\mathrm{kHz})$ & -0.186 & 1.014 & 49.831 & 34.346 \\
\hline$D_{J K}(\mathrm{kHz})$ & 2.087 & -8.374 & -252.397 & -64.170 \\
\hline$D_{K}(\mathrm{kHz}) \ldots \ldots \ldots \ldots \ldots \ldots \ldots \ldots \ldots$ & -0.197 & 18.119 & 363.661 & 54.583 \\
\hline$\delta_{J}(\mathrm{kHz})$ & -0.499 & 1.542 & -7.278 & -47.373 \\
\hline$\delta_{J}(\mathrm{kHz})$ & -0.577 & 2.961 & -12.135 & -21.751 \\
\hline
\end{tabular}

\footnotetext{
${ }^{a}$ Plummer et al. (1984).
}

b Plummer et al. (1986). 
respectively. The corresponding values for trans-methyl formate are $A=47,380.066 \mathrm{MHz}, B=4738.781 \mathrm{MHz}$, and $C=$ $4430.339 \mathrm{MHz}$; and $A=47,389.697 \mathrm{MHz}, B=4737.751 \mathrm{MHz}$, and $C=4429.607 \mathrm{MHz}$ (see Table 8).

As the parameters have been computed in the energy levels, they are comparable with experimental data, in the case of the cis form (Plummer et al.1984, 1986). To our knowledge, there is no available experimental data for trans-methyl formate. For cis-methyl formate, various studies, which present important disagreements concerning the fitted parameters, are available. The discordances arise from the different fitting techniques and are not limited to the distortion constants. The effect concerns the in-plane $A$ and $B$ rotational constants, which are the most important parameters to characterize the molecular structure. Electrostatic interactions introduce in-plane molecular distortion that has an effect in the $A / B$ ratio.

Our $A$ and $B$ parameters of 20,040.473 and $6974.140 \mathrm{MHz}$, respectively, are in good agreement with the earlier papers $(A / B=19,985.7623 / 6914.7577$, Plummer et al. $1984 ; A / B=$ 19,981.248/6914.02, Nadgaran \& Baker 1995). Recent data $(A / B=17,522.36993 / 9323.547665$, Oesterling et al. 1999; $A / B=19,120.151 / 9181.7185$, Ogata et al. 2004) are far away from the ab initio results. In these cases, a global fitting including together the $A$ and $E$ components of the two states is performed using a large number of parameters.

By taking into consideration what is the usual accuracy of the Möller-Plesset ab initio calculations for like molecules (see, e.g., our results for two isomers of methyl formate: acetic acid [Senent 2001] and glycolaldehyde [Senent 2004]), it may be asserted that the global fits do not provide a real description of the molecular structure. The significance of the rotational parameters is not realistic. The problem can be related to the torsional dependence of the molecular geometry.

For a better understanding of the problem, we provide the values of the rotational constants for the selected conformations in Table 3. For example, in the cis form, the $A$ parameter varies by $352 \mathrm{MHz}$ when the energy changes $191.7 \mathrm{~cm}^{-1}$. It is evident that the torsional dependence of the rotational constants is clearly important and has to be considered at the moment of the selection of the fitting parameters.

This work has been also supported by the Ministerio de Ciencia y Tecnología of Spain, grant AYA2002-02117, and the Consejo Nacional de Ciencia y Tecnología de México, grant n1 37075-E.

\section{APPENDIX}

TABLE A1

Selection Rules for the Infrared Transitions

\begin{tabular}{|c|c|c|}
\hline $\begin{array}{c}\text { A-Type Bands } \\
\mu_{a} A_{1}\end{array}$ & $\begin{array}{c}\text { B-Type Bands } \\
\mu_{b} A_{1}\end{array}$ & $\begin{array}{c}\text { C-Type Bands } \\
\mu_{c} A_{2}\end{array}$ \\
\hline$A_{1} \leftrightarrow A_{1} \ldots \ldots \ldots$ & $A_{1} \leftrightarrow A_{1}$ & $A_{1} \leftrightarrow A_{2}$ \\
\hline 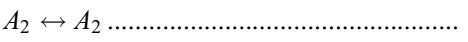 & $A_{2} \leftrightarrow A_{2}$ & $E_{x} \leftrightarrow E_{y}$ \\
\hline$E_{x} \leftrightarrow E_{y}$ & $E_{x} \leftrightarrow E_{x}$ & $\ldots$ \\
\hline
\end{tabular}

TABLE A2

Rotational Torsional Functions for Methyl Formate

\begin{tabular}{|c|c|c|c|}
\hline Symmetry & Torsional Eigenfunctions & $J$ & $K$ \\
\hline \multirow[t]{4}{*}{$A_{1} \ldots \ldots \ldots \ldots \ldots \ldots \ldots$} & $\sum\left(A_{i} \cos 3 n \theta \cos l \alpha+B_{i} \sin 3 n \theta \sin l \alpha\right)$ & Even & Even \\
\hline & $\sum\left(A_{i} \cos 3 n \theta \sin l \alpha+B_{i} \sin 3 n \theta \cos l \alpha\right)$ & Even & Odd \\
\hline & $\sum\left(A_{i} \cos 3 n \theta \cos l \alpha+B_{i} \sin 3 n \theta \sin l \alpha\right)$ & Odd & Odd \\
\hline & $\sum\left(A_{i} \cos 3 n \theta \sin l \alpha+B_{i} \sin 3 n \theta \cos l \alpha\right)$ & Odd & Even \\
\hline \multirow[t]{4}{*}{$A_{2} \ldots \ldots \ldots \ldots \ldots \ldots \ldots$} & $\sum\left(A_{i} \cos 3 n \theta \cos l \alpha+B_{i} \sin 3 n \theta \sin l \alpha\right)$ & Even & Odd \\
\hline & $\sum\left(A_{i} \cos 3 n \theta \sin l \alpha+B_{i} \sin 3 n \theta \cos l \alpha\right)$ & Even & Even \\
\hline & $\sum\left(A_{i} \cos 3 n \theta \cos l \alpha+B_{i} \sin 3 n \theta \sin l \alpha\right)$ & Odd & Even \\
\hline & $\sum\left(A_{i} \cos 3 n \theta \sin l \alpha+B_{i} \sin 3 n \theta \cos l \alpha\right)$ & Odd & Odd \\
\hline \multirow[t]{4}{*}{$E_{x} \ldots \ldots \ldots \ldots \ldots \ldots \ldots$} & $\sum\left\{A_{i} \cos [(3 n \pm 1) \theta] \cos l \alpha+B_{i} \sin [(3 n \pm 1) \theta] \sin l \alpha\right\}$ & Even & Even \\
\hline & $\sum\left\{A_{i} \cos [(3 n \pm 1) \theta] \sin l \alpha+B_{i} \sin [(3 n \pm 1) \theta] \cos l \alpha\right\}$ & Even & Odd \\
\hline & $\sum\left\{A_{i} \cos [(3 n \pm 1) \theta] \cos l \alpha+B_{i} \sin [(3 n \pm 1) \theta] \sin l \alpha\right\}$ & Odd & Odd \\
\hline & $\sum\left\{A_{i} \cos [(3 n \pm 1) \theta] \sin l \alpha+B_{i} \sin [(3 n \pm 1) \theta] \cos l \alpha\right\}$ & Odd & Even \\
\hline \multirow[t]{4}{*}{$E_{y} \ldots \ldots \ldots \ldots \ldots \ldots$} & $\sum\left\{A_{i} \cos [(3 n \pm 1) \theta] \cos l \alpha+B_{i} \sin [(3 n \pm 1) \theta] \sin l \alpha\right\}$ & Even & Odd \\
\hline & $\sum\left\{A_{i} \cos [(3 n \pm 1) \theta] \sin l \alpha+B_{i} \sin [(3 n \pm 1) \theta] \cos l \alpha\right\}$ & Even & Even \\
\hline & $\sum\left\{A_{i} \cos [(3 n \pm 1) \theta] \cos l \alpha+B_{i} \sin [(3 n \pm 1) \theta] \sin l \alpha\right\}$ & Odd & Even \\
\hline & $\sum\left\{A_{i} \cos [(3 n \pm 1) \theta] \sin l \alpha+B_{i} \sin [(3 n \pm 1) \theta] \cos l \alpha\right\}$ & Odd & Odd \\
\hline
\end{tabular}

\section{REFERENCES}

Bauder, A. 1979, J. Phys. Chem. Ref. Data, 8, 583

Blake, G. A., Sutton, E. C., Masson, C., \& Phillips, T. G. 1986, ApJS, 60, 357

Blom, C. E., \& Günthard, Hs. H. 1981, Chem. Phys. Lett., 84, 267

Brown, R. D., Crofts, J. G., Gardner, F. F., Godfrey, P. D., Robinson, B. J., \& Whiteoak, J. B. 1975, ApJ, 197, L29

Chao, J., Hall, K. R., Marsh, K. N., \& Wilhoit, R. C. 1986, J. Phys. Chem. Ref. Data, 15, 1369
Cradock, S., \& Rankin, D. W. H. 1980, J. Mol. Struct., 69, 145

Crovisier, J. 2002, BASEMOLE (ver. 4.2; Meudon: Obs. Paris-Meudon), http:// wwwusr.obspm. fr/ crovisie/basemole

Curl, R. F. 1959, J. Chem. Phys., 30, 1529

Demaison, J., Boucher, D., Dubrulle, A., \& Van Eijck, B. P. 1983, J. Mol. Spectrosc., 102, 260

Fateley, W. G., \& Miller, F. A. 1961, Spectrochim. Acta A, 17, 857 
Fausto, R., \& Teixeira-Dias, J. J. C. 1987, J. Mol. Struct. Theochem, 150, 381 Francisco, J. S. 2003, J. Am. Chem. Soc., 125, 10475

Frisch, M. J., et al. 2004, Gaussian 03 (rev. C.02; Wallingford: Gaussian, Inc.) Good, D. A., \& Francisco, J. S. 2002, J. Phys. Chem. A, 106, 1733

Hansen, J. C., Li, Y., Francisco, J. S. Szente, J. J., \& Matti Maricq, M. 2000, J. Chem. Phys., 113, 6465

Herbst, E., \& Roberts, H., 2004, in 59th Int. Symp. on Molecular Spectroscopy (Columbus: Ohio State Univ.), WI09

Hollis, J. M., Lovas, F. J., \& Jewell, P. R. 2000, ApJ, 540, L107

Horn, A., Mollendal, H., Sekiguchi, E., Uggerud, E., Roberts, H., Herbst, E., Viggiano, A. A., \& Fridgen, T. D. 2004, ApJ, 611, 605

Johansson, L. E. B., et al. 1984, A\&A, 130, 227

John, I. G., \& Radom, L. 1977, J. Mol. Struct., 36, 133

Karakawa, Y., Oka, K., Odashima, H., Takagi, K., \& Tsunekawa, S. 2001, J. Mol. Spectrosc., 210, 196

Muñoz-Caro, C., Niño, A., \& Senent, M. L. 1997, Chem. Phys. Lett., 273, 135

Nadgaran, H., \& Baker, J. G. 1995, in ASP Conf. Ser. 81, Workshop on Laboratory and Astronomical High-Resolution Spectra, ed. A. J. Sauval, R. Blomme, \& N. Grevesse (San Francisco: ASP), 329

Oesterling, L. C., Albert, S., De Lucia, F. C., Sastry, K. V. L. N., \& Herbst, E. 1999, ApJ, 521, 255

Oesterling, L. C., Ferguson, D. W., Herbst, E., \& De Lucia, F. C. 1995, J. Mol. Spectrosc., 172, 469
Ogata, K., Odashima, H., Takagi, K., \& Tsunekawa, S. 2004, J. Mol. Spectrosc., 225,14

Plummer, G. M., Herbst, E., \& De Lucia, F. C. 1987, ApJ, 318, 873

Plummer, G. M., Herbst, E., De Lucia, F. C., \& Blake, G. A. 1984, ApJS, 55, 633

1986, ApJS, 60, 949

Rocha, A. B., Pimentel, A. S., \& Bielschowsky, C. E. 2002, J. Phys. Chem. A, 106,181

Senent, M. L. 1998a, Chem. Phys. Lett., 296, 299

1998b, J. Mol. Spectrosc., 191, 265

2001, Mol. Phys., 15, 1311

2004, J. Phys. Chem. A, 108, 6286

Senent, M. L., Moule, D. C., \& Smeyers, Y. G. 1995, J. Chem. Phys., 102, 5952

Senent, M. L., Smeyers, Y. G., Dominguez-Gómez, R., \& Villa, M. 2000, J. Chem. Phys., 112, 5809

Susi, H., \& Scherer, J. R. 1969, Spectrochim. Acta A, 25, 1243

Susi, H., \& Zell, T. 1963, Spectrochim. Acta A, 19, 1933

Sutton, E. C., Blake, G. A., Masson, C., \& Phillips, T. G. 1985, ApJS, 58, 341

Szalay, V., Császár, A. G., \& Senent, M. L. 2002, J. Chem. Phys., 117, 6489

Villa, M., Herrera, G., \& Smeyers, Y. G. 1999, Chem. Phys., 306, 72

Wilmshurst, J. K. 1957, J. Mol. Spectrosc., 1, 201 